\title{
High-resolution Seismic and Ground Penetrating Radar-Geophysical Profiling of a Thermokarst Lake in the Western Lena Delta, Northern Siberia
}

\author{
G. J. Schwamborn, ${ }^{1 *}$ J. K. Dix, ${ }^{2}$ J. M. Bull ${ }^{2}$ and V. Rachold ${ }^{1}$ \\ ${ }^{1}$ Alfred Wegener Institute for Polar and Marine Science, Potsdam, Germany \\ ${ }^{2}$ School of Ocean and Earth Science, Southampton Oceanography Centre, Southampton, UK
}

\begin{abstract}
High-resolution seismic and ground-penetrating-radar (GPR) data have been acquired over Lake Nikolay in the western Lena Delta in order to study the uppermost basin fill and the bordering frozen margins. GPR (100 MHz antenna pair) measurements were completed on the frozen lake and its permafrost margins, while high-resolution seismic data were acquired from the lake during open-water conditions in summer using a $1.5-11.5 \mathrm{kHz}$ Chirp profiler. The combined use of the two profiling systems allows stratigraphic profiling in both frozen and unfrozen parts of the lake. Shallow seismic reflection images of the uppermost 4 to $5 \mathrm{~m}$ of sediments are compared to GPR sections, which have approximately the same horizontal and vertical resolution. Short sediment cores aid calibrate the geophysical data. Copyright (c) 2002 John Wiley \& Sons, Ltd.
\end{abstract}

KEY WORDS: permafrost geophysics; seismic and GPR; thermokarst lake; Siberia

\section{INTRODUCTION}

The Lena Delta is a large Arctic delta and the main connection between continental and marine environments in the Laptev Sea (Rachold et al., 1999). The climatic and sedimentary conditions of the Lena Delta are different from those of delta regions in lower latitudes because it is part of the continuous permafrost zone of northern Siberia. Permafrost thicknesses can reach more than $600 \mathrm{~m}$ in the area (Grigoriev, 1960). Lake Nikolay is the largest confined water body in the Lena Delta and is situated in the northwestern part of Arga Island (Figure 1). This lake is one of numerous lakes

* Correspondence to: G. J. Schwamborn, AWI-Polar and Marine Science, Telegrafenberg A43, 14473 Potsdam, Germany.

E-mail: gschwamborn@AWI-Potsdam.de

Contract grant sponsor: Russian and German Ministries of Science and Technologies, and the European Commission-Marie Curie Fellowship Framework Programme.

Copyright (C) 2002 John Wiley \& Sons, Ltd. belonging to a type of oriented lake which is a widespread geomorphological feature on Arga Island (Grigoriev, 1993). From west to east, Lake Nikolay is about $8 \mathrm{~km}$ wide and from north to south ca. $6 \mathrm{~km}$ long. Approximately $70 \%$ of the lake area has a water depth of less than $2 \mathrm{~m}$. Below these shallow margins an active layer exists with an average thaw depth of ca. $0.5-0.6 \mathrm{~m}$ in late summer. During winter, this shallow marginal area is completely frozen and covered by lake ice. A maximum water depth of $30 \mathrm{~m}$ is recorded in a series of sub-basins. In these sub-basins, the basin fill remains unfrozen below a water column, which has an ice cover 2 to $3 \mathrm{~m}$ thick during the winter months.

Recent studies suggest that Lake Nikolay has a thermokarst origin (Schwamborn et al., 2000). Age determinations and pollen analyses of lake sediments reveal that its formation is related to a regional climatic optimum at ca. 7 ka BP (uncalibrated radiocarbon years). Continuous sediment subsidence due Received 20 December 2001 Revised 15 September 2002 Accepted 22 September 2002 

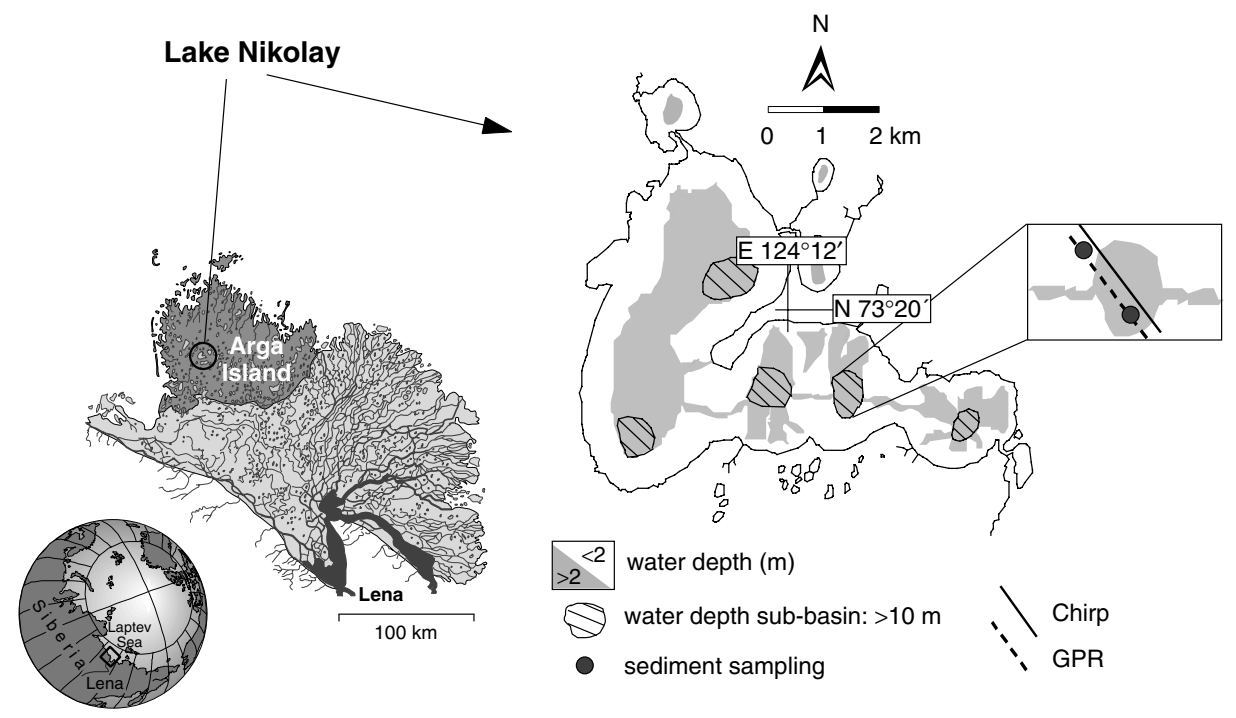

Figure 1 Map of Lake Nikolay on Arga Island (western Lena Delta). The locations of geophysical profiles and sediment coring described in the text are highlighted. The $2 \mathrm{~m}$ bathymetric line marks the boundary to which the shallow margins are completely frozen during winter. Sub-basins and shallow margins are outlined as measured by water depths with a portable infrared sounder on board a rubber boat and with the aid of aerial photography.

to thawing subground (i.e. thermokarst) is thought to have promoted the creation of the lake depression. To locate the coring site and to reveal structural information on the sediment bedding within Lake Nikolay, ground-penetrating-radar (GPR) measurements with a $100 \mathrm{MHz}$ antenna pair were acquired during the winter of 1999. These activities complement shallow seismic (Chirp) measurements collected as a presurvey of the sediment fill in the preceding summer season (see Figure 1).

GPR sounding is an established technique for permafrost investigations (Annan and Davis, 1976; Arcone et al., 1998; Judge et al., 1991; Robinson et al., 1997; Hinkel et al., 2001), active layer surveys (Doolittle et al., 1990) and lake-sediment profiling (Mellet, 1995). Mellet (1995) and Moorman and Michel (1997) have shown the potential of the GPR method for surveying sediments through a lake-ice cover. Literature on seismic surveys of lake sediments is well-established; for example Niessen et al. (1999) have used the same Chirp sound source as for this study, Abbott et al. (2000) operated with a $3-7 \mathrm{kHz}$ seismic pulse system, and Mullins and Halfman (2001) deployed a sub-bottom profiling system that has sweep frequencies of 2 to $12 \mathrm{kHz}$. A comparison of higher frequency GPR data $(50$ and $100 \mathrm{MHz})$ to a seismic system on open water (using a $7 \mathrm{kHz}$ transducer) demonstrated that these techniques often provide complementary information (Delaney et al., 1992; Sellman et al., 1992).
In this study, the combined use of Chirp and GPR data was guided by our desire to know whether a cost-intensive field campaign of seismic presurvey at a remote arctic site could be omitted from a field investigation. With regard to the GPR measurements, it was necessary to establish whether the quality of GPR profiling acquired through a winter lake-ice cover was satisfactory enough to provide the needed subsurface information for subsequent sediment coring from the ice and to eventually replace the summer seismic programme.

To find suitable answers, the following procedure was chosen. Profiles of the basin fills and profiles of the shallow margins were obtained in equal manner with both profilers. The post-processing flows for Chirp and GPR data were adjusted to assure a thorough comparison of the data sets. The vertical and horizontal resolutions of the Chirp and the GPR data were lined up to show that they delivered similar resolution characteristics even though the propagation velocities are very different. Short sediment cores were used to aid geophysical data interpretation.

\section{SEISMIC DATA ACQUISITION}

A Chirp sub-bottom profiler (GeoChirp ${ }^{\mathrm{TM}}$ by GeoAcoustics) with a $32 \mathrm{~ms} 1.5-11.5 \mathrm{kHz}$ sweep source was used to collect $25 \mathrm{~km}$ of profiles across the 
lake. The system, which can be used on open water only, was mounted upon a surface-towed catamaran, attached to which was an eight-element, single-channel $0.5-15 \mathrm{kHz}$ hydrophone streamer. The whole system was operated from a small inflatable boat. The transmission trigger rate was set to four chirps per second and the survey speed was approximately $1.6 \mathrm{~ms}^{-1}$. A global positioning system (GPS) receiver provided survey navigation.

Chirp profilers are digital, frequency-modulated (FM) sources with a predetermined and repeatable source signature for high-resolution, normal incidence seismic reflection data acquisition. The Chirp systems comprise calibrated, linear electronic components and transmit signals containing pre-determined phase and amplitude corrections (Quinn, 1997). This ensures that no anomalies occur in the transducers or the transmitting and receiving electronics. The signal-to-noise $(\mathrm{S} / \mathrm{N})$ ratio of Chirp data is improved through matched filter processing by correlating the reflection data with the pre-determined transmitted pulse (Schock and LeBlanc, 1990). If reflections or noise do not match the outgoing Chirp waveform, the filter attenuates the unwanted signal. See Quinn (1997) and Quinn et al. (1998) for a description on
Chirp profiling generally and Niessen et al. (1997) for a description of the specific system used.

The post-processing flow applied in the laboratory has been designed to improve data clarity and lateral continuity specifically for high-resolution Chirp data (Quinn, 1997; Quinn et al., 1998; Lenham, 2000). The processing sequence includes bandpass filtering (Ormsby), F-X (frequency-distance) deconvolution, automatic gain control (AGC), a Stolt F-K (frequency-wave number) migration, an $\mathrm{F}-\mathrm{K}$ filtering and the application of a dynamic S/N filter (Figure 2). The first three algorithms in the processing sequence are standard seismic processing applications (Yilmaz, 1987). The application of the dynamic $\mathrm{S} / \mathrm{N}$ filter as a final step is less standard and is particularly suitable to Chirp data (Quinn, 1997). For converting the TWT (two way travel) times into depth, $p$-wave velocities of $1420 \mathrm{~ms}^{-1}$ and $1490 \mathrm{~ms}^{-1}$ are assumed for the water column and the lake sediments respectively, after Niessen and Melles (1995).

\section{GPR DATA ACQUISITION}

GPR profiling was conducted along flagged traverse lines within Lake Nikolay using the $100 \mathrm{MHz}$
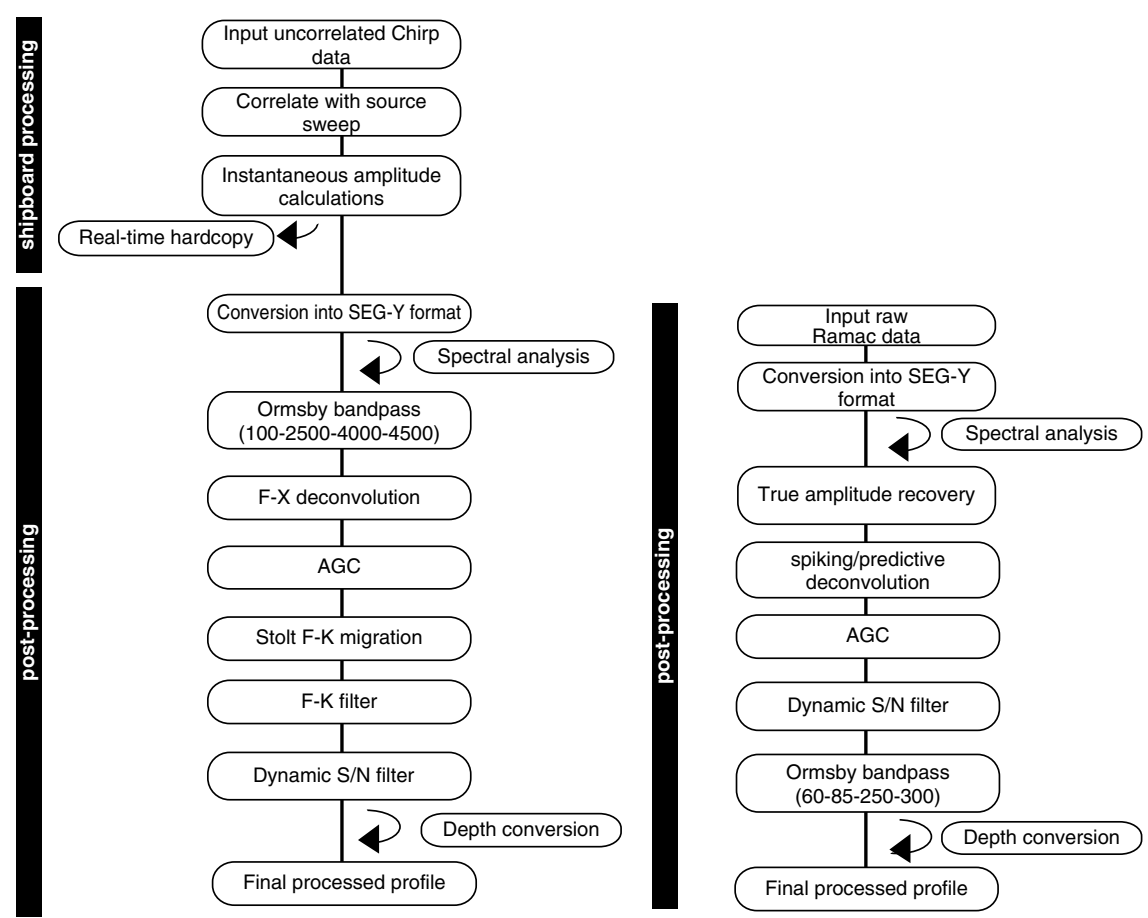

Figure 2 The GPR data processing flow (right) resembles the Chirp data processing flow (left) and enables a more thorough comparison of the digital data. SEG-Y stands for a tape standard developed by the Society of Exploration Geophysicists (SEG). 
Table 1 GPR system settings for lake sediment profiling.

\begin{tabular}{lc}
\hline Antenna pair & $100 \mathrm{MHz}$ \\
\hline Antenna offset & $1 \mathrm{~m}$ \\
Samples per trace & 1536 \\
Stacks & 128 \\
Sampling frequency & $1016 \mathrm{MHz}$ \\
\hline
\end{tabular}

antenna pair from RAMAC (Malå/Geoscience). A GPS receiver provided the navigation. Data were collected with settings as listed in Table 1. They were found to offer the best trade-off between $\mathrm{S} / \mathrm{N}$ ratio and time required for data acquisition. Since the lake water has low conductivity $(<50 \mu \mathrm{S} / \mathrm{cm})$ good penetration of the GPR signals was permitted through the water column. In total thirteen GPR profiles $(23 \mathrm{~km}$ total) of the lake basins and the surrounding margins were collected. GPR profiling was completed using a diesel vehicle, the antenna pair being mounted on a textile sheet and towed behind the vehicle. The transmitting and receiving antennae had a constant offset of $1 \mathrm{~m}$ and were arranged perpendicular to the profile direction.

The GPR data were imported into seismic processing software $\left(\right.$ ProMAX $\left.{ }^{\mathrm{TM}}\right)$ and an optimal processing flow determined according to the seismic processing procedure (Figure 2). This comprised a true amplitude recovery, a spiking/predictive deconvolution, AGC, dynamic S/N filtering and finally a (Ormsby) bandpass filter.

\section{SEDIMENT SAMPLING}

Sampling of frozen and unfrozen sediments was performed using a frozen-ground rotary coring kit consisting of an engine power-auger unit, iron rods, and iron core barrels. The stable winter ice cover of the lake served as the coring platform. Core sections were cleaned, described and stored immediately after sectioning into $5 \mathrm{~cm}$ intervals. After transit to the laboratory the individual samples were examined for moisture (gravimetric water content) expressed in weight per cent ( $\left.\mathrm{wt}^{\%} \%\right)$.

\section{EM VELOCITY ANALYSES}

In order to determine the velocity depth function for the electro-magnetic (EM) waves several common mid-point (CMP) measurements were recorded.

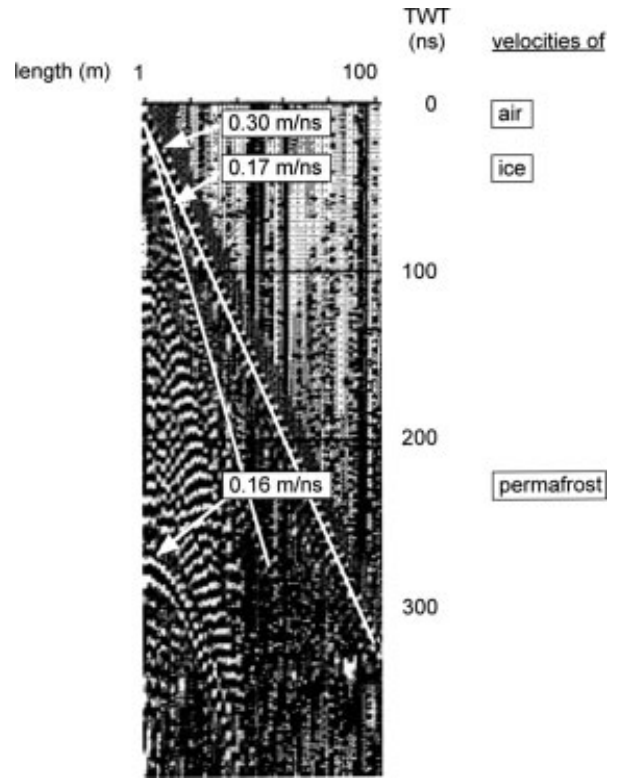

Figure 3 Example of CMP deduced subsurface velocities. Measurements have been conducted over a shallow margin of Lake Nikolay where frozen sediments lie directly underneath the lake ice. For position see Figure 5.

Antenna spacing was changed with constant increments of $1 \mathrm{~m}$ to offsets of $100 \mathrm{~m}$ at maximum. This generated an antenna-separation versus travel-time plot, from which the propagation velocity of subsurface materials can be deduced (Annan and Davis, 1976). These profiles were recorded at characteristic sites such as deep basins or the shallow margins (Figure 3). The main drawback of this technique is that velocity determination of deeper layers becomes increasingly difficult due to the weakening strength of returns, the presence of refractions, and the complicated geometry of the travel paths of reflections (Moorman and Michel, 1997). Consequently, direct calculations of signal propagation velocity were made by comparing the TWT times between reflections on GPR profiles with measured thicknesses of the lakeice cover, the water column, and the sediment layers in the core (Figure 4). The thickness of lake ice and the water depth were measured manually with a plumb line and a measuring tape. During the summer measurements, the thickness of the active layer at the shallow margins was determined in a comparable way with a prick rod. Two cores, one into the basin sediments, and one into a frozen margin, enabled us to identify the materials and sedimentary boundaries, respectively. The propagation velocities for the EM waves used in this study are listed in Table 2 along 
Table 2 EM velocity values used to estimate depth scales with literature values according to Davis and Annan (1989) for comparison.

\begin{tabular}{lccc}
\hline Material & Determination method & EM velocity $(\mathrm{m} / \mathrm{ns})$ & Literature value \\
\hline Air & CMP & 0.30 & 0.30 \\
Ice & CMP & 0.17 & 0.16 \\
Frozen ground below ice & CMP & 0.16 & $0.11-0.15^{*}$ \\
Saturated sand & Direct measurement & 0.06 & 0.06 \\
Fresh water & Direct measurement & 0.036 & 0.033 \\
\hline
\end{tabular}

* According to RAMAC/GPR Operating Manual (1997).

with the method of determination and extant values published in Davis and Annan (1989).

\section{RESOLUTION OF GPR AND SEISMIC DATA}

\section{Vertical Resolution}

The depth (or vertical) resolution of both EM and seismic waves is dependent on the wavelength $(\lambda)$ in the different media so the approximate vertical resolution can be calculated from the following formula:

$$
\lambda=v / f
$$

where $v$ is the propagation velocity $\left[\mathrm{ms}^{-1}\right]$ of the wavelet within the material, and $f$ is the antenna frequency $[\mathrm{Hz}]$ used. The theoretical depth resolution is about one-quarter of the wavelength in the different media (Sheriff and Geldart, 1995). Deconvolution processing has been applied to both Chirp and GPR data sets to enhance them. Using the dominant
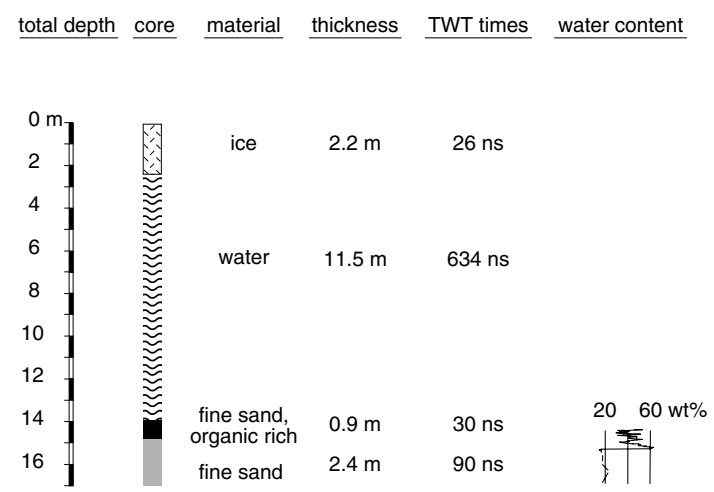

Figure 4 Coring results for the lake sediment site, the respective material thicknesses and the deduced TWT times in the GPR section. frequency of the direct wave arriving at the system's receiver has approximated the dominant wavelength. In case of the here-used Chirp profiler, the dominant frequency was found to be $3 \mathrm{kHz}$ by screen control. Likewise the GPR centre frequency of $100 \mathrm{MHz}$ has been confirmed.

In order to approximate the theoretical resolvable bed thicknesses that can be estimated with the different profiling systems the velocity information relevant to the profiling system and the sub-bottom environment was taken. The obtained theoretical depth resolution for GPR data amounts to $0.12 \mathrm{~m}$ in the saturated uppermost basin fill and to $0.3 \mathrm{~m}$ in frozen deposits. The same equation applied to the Chirp data of lake sediments results in $0.12 \mathrm{~m}$ depth resolution (see also Table 3). However, in most terrains the vertical resolution is found to be two or three times the theoretical vertical resolution, depending upon surface roughness and slope, volume scattering, pulse bandwidth, dispersivity, properties contrast, etc.

The ability to compare physical event identification using the two systems, Chirp and GPR, is caused by having similar wavelengths in the same environment. The dominant $3 \mathrm{kHz}$ frequency of the Chirp corresponds to a wavelength of $0.5 \mathrm{~m}$ in saturated sands and the $100 \mathrm{MHz}$ dominant frequency of the GPR corresponds to a wavelength of $0.6 \mathrm{~m}$ in the same environment, although the relevant propagation velocities are very different $\left(1490 \mathrm{~ms}^{-1}\right.$ and $0.06 \mathrm{mns}^{-1}$, respectively).

\section{Horizontal Resolution}

Spatial (or horizontal) resolution refers to the reflected energy that arrives from a circular zone (Fresnel zone) on the reflector. Its radius increases with depth. The radius $r$ of the first Fresnel zone can be approximated by:

$$
r=[v / 2][t / f]^{0.5}
$$


Table 3 Resolution of GPR and Chirp data in different environments. Vertical resolving limit is assumed to be one quarter of the dominant wavelength. Horizontal resolution $(=2 \mathrm{r})$ of the sediments is dependent on the depth position and the materials above with their relevant propagation velocities (listed in italic letters).

\begin{tabular}{lccc}
\hline System & GPR $(100 \mathrm{MHz})$ & GPR $(100 \mathrm{MHz})$ & Chirp $(1.5-11.5 \mathrm{kHz})$ \\
\hline Dominant return frequency & $100 \mathrm{MHz}$ & $100 \mathrm{MHz}$ & $3 \mathrm{kHz}$ \\
Environment & Frozen basin margins & \multicolumn{2}{c}{ Lake sediments } \\
Propagation velocity & $0.16 \mathrm{~m} / \mathrm{ns}$ & $0.06 \mathrm{~m} / \mathrm{ns}$ & $1490 \mathrm{~m} / \mathrm{s}$ \\
Vertical resolution & $0.4 \mathrm{~m}$ & $0.15 \mathrm{~m}$ & $0.12 \mathrm{~m}$ \\
Horizontal resolution & $5.7 \mathrm{~m}$ & $2.8 \mathrm{~m}$ & $3.1 \mathrm{~m}$ \\
$\quad \begin{array}{l}\text { Depth position and } \\
\text { relevant propagation velocity }\end{array}$ & $10 \mathrm{~m}$ of frozen ground & $10 \mathrm{~m}$ of water column \\
$\quad$ in the overlying material & $0.16 \mathrm{~m} / \mathrm{ns}$ & $0.036 \mathrm{~m} / \mathrm{ns}$ & $1420 \mathrm{~m} / \mathrm{s}$ \\
Horizontal shot interval & $1 \mathrm{~m}$ & $1 \mathrm{~m}$ & $0.4 \mathrm{~m}$ \\
\hline
\end{tabular}

where $v$ is the wave velocity $\left[\mathrm{ms}^{-1}\right]$ along its path, $t$ is the TWT time [s] for the wave reflected from a given depth and $f$ is the frequency [Hz] of the wave. From equation (2), it can be seen that the spatial resolution decreases as a function of depth (i.e. the increase in time) but is modified by the different wave velocities in the different media. Calculated examples are given in Table 3.

The derivation of the Fresnel zone radius approximation is analogous for both seismic and EM waves, although this equation gives only a rough estimate of the horizontal resolution limit. It actually depends on many factors; for example, in the case of Chirp data the beam angle and, therefore, the footprint of the system, are also dependent upon the transducer array and the bandwidth of the source (Quinn, 1997). In the case of GPR data, it is dependent on the direction and shape of the EM cone transmitted into the ground (Arcone, 1995).

A final factor effecting horizontal resolution of the profiles is the horizontal shot interval. In the case of the Chirp survey, this factor is dependent upon survey speed (in our measurements $1.6 \mathrm{~ms}^{-1}$ ) and the chosen pulse rate (in our measurements four shots per second, i.e. $0.4 \mathrm{~m}$ per trace). In the case of the GPR surveys, it is the chosen shot spacing (in our measurements $1 \mathrm{~m}$ per trace). The shot interval for both profilers is smaller than the calculated horizontal resolution $(=2 r)$, or Fresnel zone, respectively. The horizontal portions equivalent to the 'effective' Fresnel zone are, thus, covered several times by subsequent traces. The coverage increases with closer spaced shot intervals. Hence, it is a significant factor in the effective horizontal resolution and should be considered in data interpretation, in our case especially in the seismic profiles.

\section{RESULTS AND DISCUSSION}

Aerial photographs show dark areas at the centre of the Lake Nikolay surrounded by brighter areas towards the shore. The brightness is interpreted as being correlating with lake bathymetry. The results from GPR and seismic measurements confirm this interpretation showing a relatively deep central lake basin $(10$ to $30 \mathrm{~m})$ surrounded by shallower areas. The irregular shape of the lake floor often shows one or two morphological steps framed by steep slopes before reaching the deepest part of the basin. Not all of the survey results are shown here; rather, one example is displayed where certain geophysical features are verified by sediment drilling. In this example, a Chirp line is compared with a radargram that has been obtained over the same lake basin (Figure 5). Because of inaccuracies during online-positioning with GPS between the two field seasons the locations of the profiles differ by $\pm 100-200 \mathrm{~m}$. This can be seen, for example, by slight differences following the basin floor surface. However, both profile lines are complementing one another, since the depositional situation does not change decisively as inferred from additional profile lines not shown here.

\section{Profiling of the Frozen Basin Margin}

A comparison of Chirp with GPR measurements of the shallow frozen basin margin can be made when regarding the left part of Figure 5. At the top, the seismic profile obtained during open water conditions is displayed and, at the bottom, the equivalent radargram is displayed as obtained during the winter season from the lake ice. Below a shallow water column of less than $2 \mathrm{~m}$, the Chirp profile exhibits a strong reflection response within a shallow 


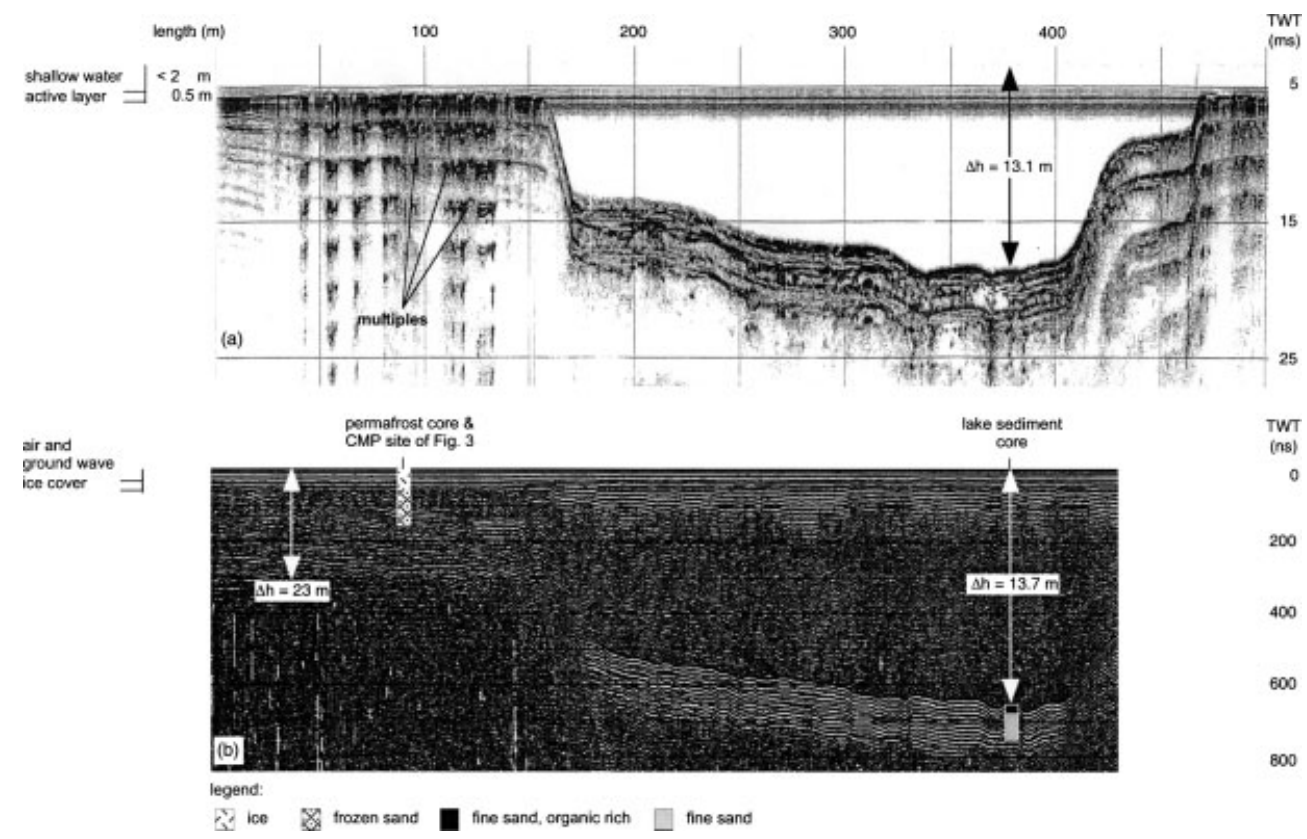

Figure 5 The Chirp (a) and the GPR (b) profile have been obtained over the same lake basin and complement each other since the depositional situation does not change decisively. Bathymetric information, EM penetration into frozen ground and position of short cores with their lithofacies are added.

sediment depth. This is due to the permafrost table which was at a depth of $0.5 \mathrm{~m}$ during the summer season. Previous seismic studies have shown that seismic systems will not trigger reliably in less than approximately $2 \mathrm{~m}$ water depth (Delaney et al., 1992; Quinn, 1997) making quantitative assessments unreliable for that water depth. In our case, the returning echo in that shallow depth appears as a convolution of the direct pressure wave, its reflection from the lake surface and from the shallow lake bottom and, finally, the shallow permafrost table underneath as mentioned above. It causes almost total reflection of the seismic waves, thus, preventing imaging of internal structures within the frozen basin margins using the seismic system. Multiples of the permafrost table are observed beneath and ringing effects may explain the further distortions, which come to pass down the section.

In contrast, sub-bottom information of the shallow margin is revealed in the GPR profile. From the top the radargram begins with continuous highamplitude events, which are the direct air wave arrivals. This occurs because the EM velocity in air (the speed of light $=0.30 \mathrm{~m} / \mathrm{ns}$ ) is much faster than in any geological material. Thus, the waves travelling directly through air between the two antennae are the first to arrive. They are followed by the ground wave on top of the ice cover. Below the lake ice cover, the frozen basin margin has a number of internal horizontal to inclined reflectors. The lowest reflectors are found at a depth of ca. $23 \mathrm{~m}$ and mark the depth of resolved EM penetration with the $100 \mathrm{MHz}$ antenna pair in the frozen subground. At the permafrost coring location, as marked in the radargram, the lake ice has a thickness of $1.2 \mathrm{~m}$ and is lying directly on frozen ground. The frozen subsurface is made of fine sand and has been drilled down to a sediment depth of $7 \mathrm{~m}$. The internal reflectors exhibited in the frozen margin are interpreted as inclined fluvial bedding planes of the frozen sand observable only by GPR means but not in the core. This sedimentary detail is likely to be caused by electrical-impedance contrasts at the sedimentary boundaries.

\section{Profiling of the Uppermost Basin Fill}

In Figure 6(a-d) a pair of Chirp and GPR profiles is displayed. These magnify the sediment fill seen in Figure 5 on the right side. The seismograms at the top are displayed as the default printout from the field (a) and as the post-processed section (b). The radargrams at the bottom display both the unprocessed (c) and processed GPR section (d). With both techniques, water depth and morphology of 

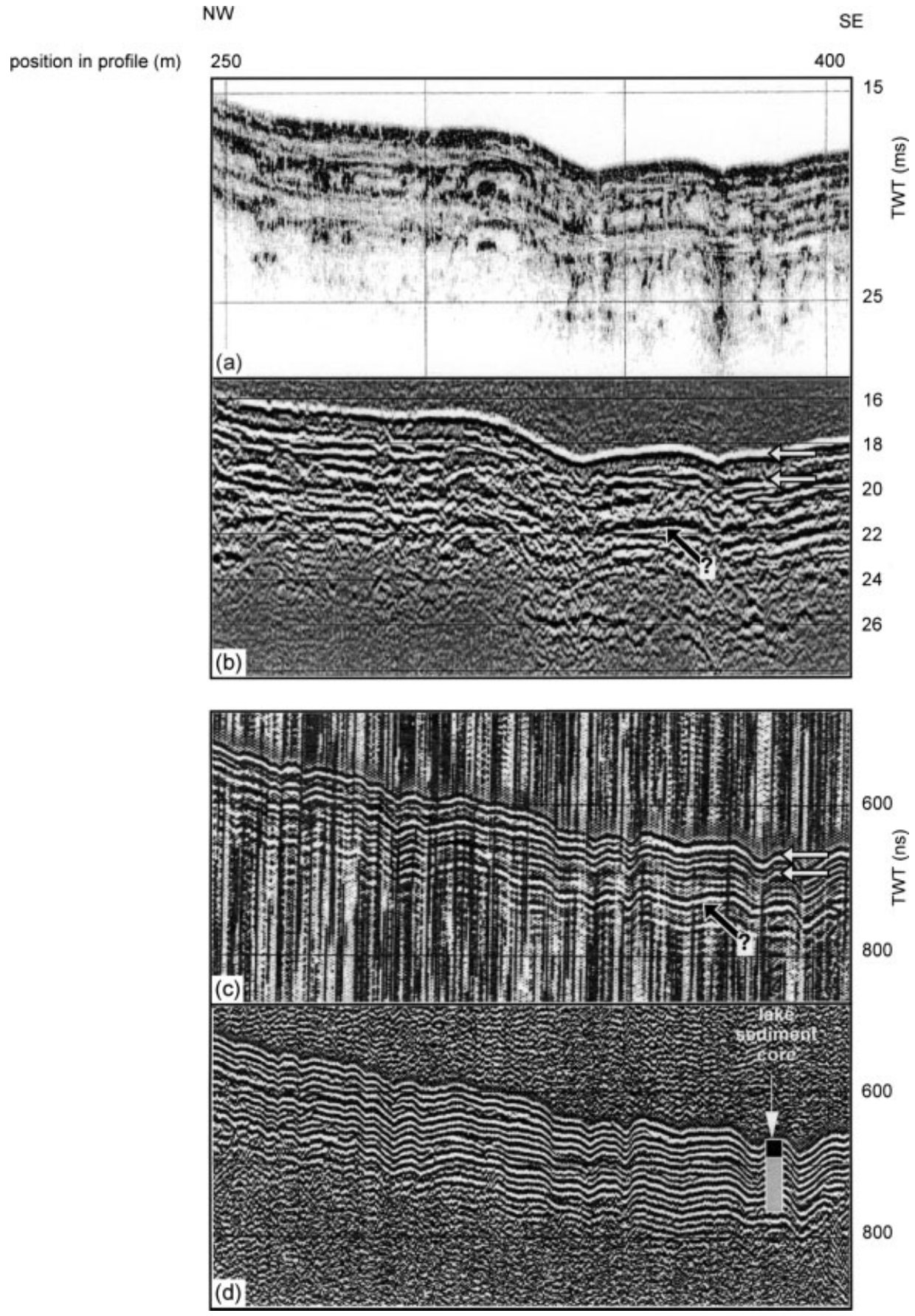

Figure 6 Comparison of Chirp ( $\mathrm{a}$ and $\mathrm{b}$ ) and GPR ( $\mathrm{c}$ and d) data from survey lines of the same lake basin at Lake Nikolay. The separation of the lines is due to GPS inaccuracies; (a) raw correlated Chirp section, (b) processed Chirp section, (c) raw GPR section, (d) processed GPR section with the position of the lake sediment core marked. White arrows indicate explained horizons, whereas black arrows with question marks indicate unexplained horizons. For more discussion see the text. 
the basin can be well determined and compared. The water depth deduced from the seismogram is $13.1 \mathrm{~m}$ (see also Figure 4), the value deduced from the radargram is $13.7 \mathrm{~m}$ for the approximate same locality. This approximate profile match includes the GPS inaccuracies and that the winter elevation of the ice surface to the summer level of the water as the horizontal reference level is not further taken into account. The lake sediments have been sampled and relevant material thicknesses are given in Figure 4. The location of lake sediment coring is marked in Figures 5 and $6 \mathrm{~d}$.

When comparing the magnified profiles of the lake sediments, both records offer straight visual interpretability, especially after enhancement of the data. There is a lateral variability in reflector coherency along the Chirp section due to noise (Figure 6a). Figure $6 \mathrm{~b}$ has improved in $\mathrm{S} / \mathrm{N}$ ratio and reflector continuity is enhanced. The same is valid for the GPR section (Figures 6c and 6d). Both the Chirp and the GPR profile allow defining major physical boundaries within the sediment fill as marked by arrows. On top of the sediments one strong reflector is revealed followed by a weaker amplitude event in the uppermost section of the sedimentary basin. The upper one is interpreted as the beginning of the lake sediments, the second one the base of it (Figures $6 \mathrm{~b}$ and $6 \mathrm{c}$, see the two white arrows). The upper seismic unit amounts to $0.8 \mathrm{~m}$ in thickness. The thickness between the upper two pronounced reflectors as picked from the raw GPR section is $0.9 \mathrm{~m}$. This was calculated combining the TWT time with the drilling results in order to calculate the EM wave velocity as introduced earlier. The upper unit in the geophysical profiles can be linked to a lacustrine organic-rich sand cover as revealed from the core (Figure 4). It represents the lake sedimentation from the modern state backward in time. In contrast, the sandy sediments following below in the core section are interpreted to belong to fluvial and/or aeolian deposits. This characterizes the environment in which the lake depressions evolved (Schwamborn et al., 2000).

Since the water content decreases from $40-60 \mathrm{wt} \%$ in the organic-rich fine sand of the upper part of the core to about $20 \mathrm{wt} \%$ in the organic-poor fine sands of the lower part of the core, this sharp physical contrast is regarded as the cause for the second strong reflections in both geophysical records. The water content largely controls the dielectric contrast from different geologic material as measured by the GPR method (Davis and Annan, 1989). Similarly the elastic boundaries as measured by seismic means, and which are defined by the density and velocity contrast, are themselves closely related to the porosity and, thus, to the water content (Niessen et al., 1999).

The Chirp imagery appears to characterize the bottom sediments further down as being more chaotic sediments with short, disconnected and bent reflectors next to horizontally to subhorizontally aligned reflectors. It is suggested that closely-spaced grain size and sorting differences affect the porosity of the fine sandy sediment as seen in the relevant part of the core. However, this interpretation may only be acceptable as long as there is no direct ground-truth verification available for the Chirp track. The basin sediments are resolved within the Chirp profile to a depth of ca. $4.5 \mathrm{~m}$ (6 ms TWT).

In the comparable part of the GPR section the reflections show lateral continuity and coherent horizontal wavelet successions (Figure 6d). The processed profile shows some of the lower reflectors pinching out especially in the left part of the section. This argues for true signal penetration rather than reverberations of the EM energy within the basin sediments. Inspection of the raw data wavelets supports the suggestion that the reflected arrivals within the lake sediments arose from real sediment boundaries, although the incoming signal wavelet is irregular and is partly lengthened (Figure 7). This is due to reverberations in the lake ice caused by the high dielectric contrast between the lake ice (relative permittivity $\varepsilon_{r}=3-4$ ) and the lake water $\left(\varepsilon_{r}=81\right)$. As the depth resolution of the GPR is in the order of $0.12 \mathrm{~m}$, the internal reflections from within the basin sediments (enhanced in the processed Figure 6d) are thought to represent apparent layering and not individual bedding planes, which could have been verified. This is supported by a lack of bedding planes as observed within the lake sediment core. However, the apparent stratigraphic resolution in the lake sediments may also be induced by polarization effects as suggested by Delaney et al. (1992). This is especially true for the parallel reflection pattern in the right part of the section, where internal multiples cannot be discounted. Furthermore, a strong reflection horizon cannot be explained yet (marked by the dark arrow with a question mark). The sediment coring reached beyond the relevant depth but no obvious macroscopic sediment boundary can be observed. Although the high amplitude event appears in both Chirp and GPR records, its nature remains obscure. The maximum resolved depth of the EM waves into the basin sediments is about $4.2 \mathrm{~m}$ (140 ns TWT).

In general, the Chirp and GPR profiles show similar penetration capabilities within the uppermost 4 to $5 \mathrm{~m}$ of basin sediments. The calculated resolution characteristics match fairly well for both profilers 


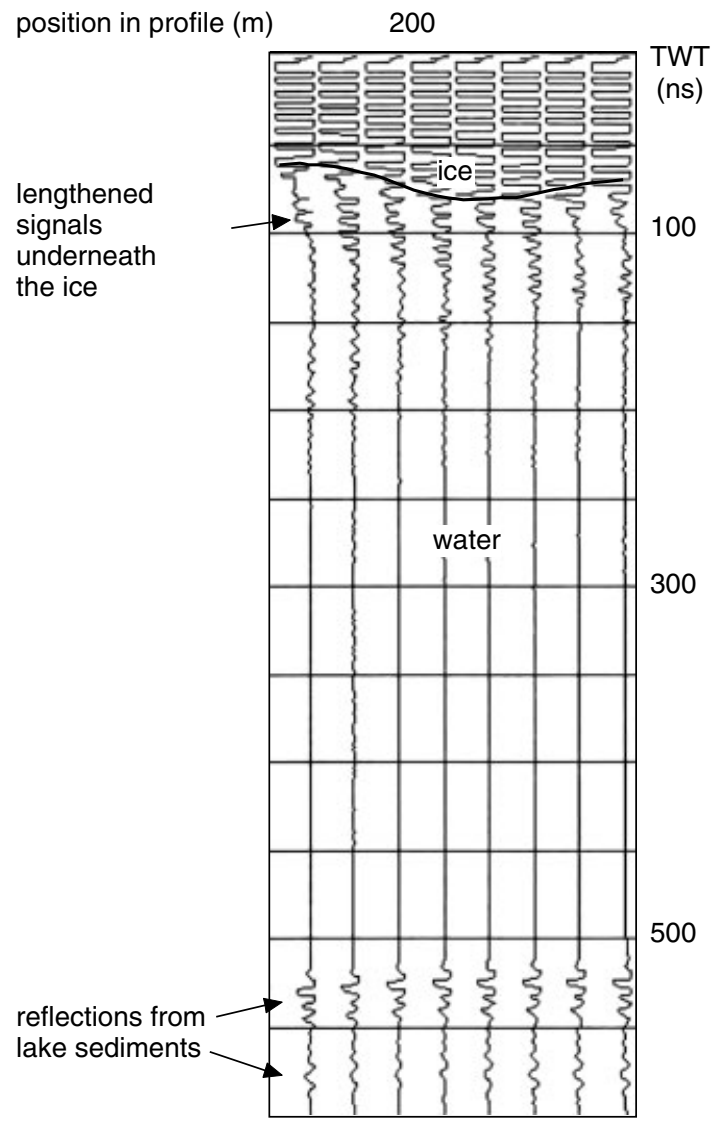

Figure 7 GPR reflections from within the lake sediments show coherent horizontal wavelet successions. This suggests that the lake sediment reflections are not superimposed by the lengthened signals originated at the ice/water interface.

as presented in Table 3. More subtle stratigraphic detail is revealed in the Chirp profile providing better definition of discrete targets just beneath the basin floors. This is likely a result of improved $\mathrm{S} / \mathrm{N}$ ratio due to known pulse output allowing effective correlation and a smaller trace interval applied. We ignore the difference in profile positions at this place. A continuing upper unit can be distinguished from a lower unit with various high-amplitude elements and detached, broken to subhorizontal orientated reflectors. In contrast, GPR raw data of the basin fill show less variability but higher horizontal continuity of reflectors. They also allow one to discriminate between an upper and a lower unit. Processed profiles can be interpreted less straightforwardly, since the records may suffer from polarization limited resolution and internal multiples may be enhanced.

The upper unit in the geophysical profiles can be linked to the lacustrine organic-rich sand of the core. The lower unit shows organic-poor fine sand suggesting a material derived from a fluvial and/or aeolian environment.

\section{CONCLUSIONS}

The Chirp and the GPR sections produce consistent but different images of the Lake Nikolay basin environment. Correlation of the Chirp and GPR data with core data is seen on the scale of only some stratigraphic boundaries. It is remarkable that the amount of resolved features with both profilers is better than could be verified by core data. A more comprehensive investigation of lake-sediment cores (i.e. density logging, dielectric changes) is needed to further understand the origin of internal reflectors. From a practical viewpoint, GPR profiling from the lake ice is capable of allowing one to dispense with a preceding seismic pre-survey on open water. Both frozen and unfrozen parts of the investigated thermokarst lake could be imaged and stratigraphic details resolved. This makes the GPR system a superior tool when working in arctic lake settings. It allows continuous profiling from basin to shallow areas. Thus, it also saves costs and enables geophysical profiling and subsequent sediment coring during only one field season on the ice. To improve horizontal resolution of the GPR data, it will be useful to perform data acquisition at finer sampling intervals.

\section{ACKNOWLEDGEMENTS}

This study is part of the project SYSTEM LAPTEV SEA 2000, which was funded by the Russian and German Ministries of Science and Technologies (BMBF-Verbundvorhaben SYSTEM LAPTEV SEA 2000). Subsequent funding for G. J. Schwamborn has been received as a 'Marie Curie training fellowship' at the Southampton Oceanography Centre, School of Ocean and Earth Sciences, Southampton. The financial support is greatly acknowledged. Two anonymous reviewers are thanked for their careful reviewing and valuable suggestions for improvements.

\section{REFERENCES}

Abbott MB, Finney BP, Edwards ME, Kelts KR. 2000. Lake-level reconstructions and paleohydrology of Birch Lake, Central Alaska, based on seismic reflection profiles and core transects. Quaternary Research 53: 154-166. 
Annan AP, Davis JL. 1976. Impulse radar sounding in permafrost. Radio Science 11: 383-394.

Arcone SA. 1995. Numerical studies of the radiation patterns of resistively loaded dipoles. Journal of Applied Geophysics 33: 39-52.

Arcone SA, Lawson DE, Delaney AJ, Strasser JC, Strasser JD. 1998. Ground-penetrating radar reflection of groundwater and bedrock in an area of discontinuous permafrost. Geophysics 63: 1573-1584.

Davis JL, Annan AP. 1989. Ground-penetrating-radar for high-resolution mapping of soil and rock stratigraphy. Geophysical Prospecting 37: 531-551.

Delaney AJ, Sellmann PV, Arcone SA. 1992. Sub-bottom profiling: A comparison of short-pulse radar and acoustic data. Proc. of the Fourth International Conference on Ground Penetrating Radar, Rovaniemi (Finland), Hänninen P, Aňtio S (eds). Geological Survey of Finland Special Paper 16: 149-157.

Doolittle JA, Hardisky MA, Gross MF. 1990. A groundpenetrating radar study of active layer thicknesses in areas of moist sedge and wet-sedge tundra near Bethel, Alaska, U.S.A. Arctic and Alpine Research 22(2): $175-182$

Grigoriev MN. 1993. Cryomorphogenesis of the Lena River Mouth Area. SB RAS: Yakutsk; 176 (in Russian).

Grigoriev NF. 1960. The temperature of permafrost in the Lena Delta basin-deposit conditions and properties of the permafrost in Yakutia. Yakutsk 2: 97-101 (in Russian).

Hinkel KM, Doolittle JA, Bockheim JG, Nelson FE, Paetzold R, Kimble JM, Travis R. 2001. Detection of subsurface permafrost features with ground-penetrating radar, Barrow, Alaska. Permafrost and Periglacial Processes 12: 179-190.

Judge AS, Tucker CAM, Pilon JA, Moorman BJ. 1991. Remote sensing of permafrost by ground-penetrating radar at two airports in Arctic Canada. Arctic 44(1): $40-48$.

Lenham JW. 2000. High resolution seismology, archaeology and submerged landscapes - an interdisciplinary study. Unpublished Ph.D. thesis, University of Southampton, $226 \mathrm{p}$.

Mellet JS. 1995. Profiling of ponds and bogs using ground-penetrating radar. Journal of Paleolimnology 14: 233-240.

Moorman BJ, Michel FA. 1997. Bathymetric mapping and sub-bottom profiling through lake ice with groundpenetrating radar. Journal of Paleolimnology 18: 61-73.

Mullins HT, Halfman JD. 2001. High-resolution seismic reflection evidence for Middle Holocene environmental change, Owasco Lake, New York. Quaternary Research 55: 322-331.

Niessen F, Melles M. 1995. Lacustrine sediment echosounding and physical properties. In The Expedition
Arctis - X/2 of RV Polarstern '94, Hubberten H-W (ed.). Reports on Polar Research, AWI: Bremerhaven; 174: 69-75.

Niessen F, Kopsch CA, Ebel T, Federov GB. 1997. Subbottom profiling in Levinson-Lessing and Taymyr lakes. In Russian German Cooperation: The Expedition Taymyr / Severnaya Zemlya, Melles M, Hagedorn B, Bolshiyanov DYu (eds). Reports on Polar Research, AWI: Bremerhaven; 237: 70-78.

Niessen F, Ebel T, Kopsch CA, Fedorov GB. 1999. Highresolution seismic stratigraphy of lake sediments on the Taymyr Peninsula, Central Siberia. In Landocean Systems in the Siberian Arctic: Dynamics and History, Kassens H, Bauch H, Dmitrenko I, Eicken H, Hubberten H-W, Melles M, Thiede J, Timokhov L (eds). Springer-Verlag: Berlin; 437-456.

Quinn RJ. 1997. Marine high-resolution reflection seismology: acquisition, processing and applications. Unpublished Ph.D. thesis. University of Southampton.

Quinn R, Bull JM, Dix JK. 1998. Optimal processing of marine high-resolution seismic reflection (chirp) data. Marine Geophysical Researches 20: 13-20.

Rachold V, Grigoriev MN, Antonow M. 1999. Modern Sedimentation and Environmental History of the Lena Delta. In Russian-German Cooperation SYSTEM LAPTEV SEA 2000: The Lena Delta 1998 Expedition, Rachold V, Grigoriev MN (eds). Reports on Polar Research, AWI: Bremerhaven; 315: 81-82.

RAMAC/GPR Operating Manual 1997. Version 2.28. Malå Geoscience. Appendix 1.

Robinson SD, Burgess MM, Judge AS, Kettles IM, Moorman BJ, Wolfe SA. 1997. The use of ground penetrating radar in permafrost environments: recent applications. Program and Abstract $27^{\text {th }}$ Arctic Workshop, Department of Geography, University of Ottawa, Feb. 27-March 2, 1997 Lewkowicz AG, Kokelj SV (eds). University of Ottawa; 191-193.

Schock SG, LeBlanc LR. 1990. Chirp Sonar: new technologies for subbottom profiling. Sea Technology 31(9): 37-43.

Schwamborn G, Tumskoy V, Andreev AA, Rachold V, Grigoriev MN, Pavlova EY, Dorozkhina MV, Hubberten H-W. 2000. Evolution of Lake Nikolay, Arga Island, Western Lena River delta, during Late Weichselian and Holocene time. Polarforschung 70: 69-82.

Sellmann PV, Delaney AJ, Arcone SA. 1992. Sub-bottom surveying in lakes with ground-penetrating-radar. CRREL Report, 92-8, Hanover: New Hampshire; 18.

Sheriff RE, Geldart LP. 1995. Exploration Seismology. Cambridge University Press, 592 p.

Yilmaz O. 1987. Seismic data processing. Investigations in Geophysics 2, Society of Exploration Geophysicists: Tulsa, Oklahoma; 526 pp. 